\title{
Analysis of complications following vaginal hysterectomy in pelvic organ prolapse
}

\section{RC LK', Das CR ${ }^{2}$}

'Laxmi RC (Karki), Assistant Professor, Department of Gynecology and Obstetrics Patan Academy of Health Sciences; ${ }^{2}$ Chitra Ranjan Das, Professor; Department of Gynecology and Obstetrics Nepalgunj Medical College Kohalpur.

\section{ABSTRACT}

Background: Vaginal hysterectomy is one of the most common gynecological procedures performed in Nepal. The most common indication is pelvic organ prolapse (POP). The common complications associated with vaginal hysterectomy are hemorrhage, infections and injury to adjacent organs.

Objectives: The aim of this study was to study the type of complications following vaginal hysterectomy in pelvic organ prolapse.

Methods: A Prospective observational study was carried out at Lord Buddha Educational Academy Nepalgunj Medical College, Kohalpur, Banke, Nepal from November 2008 to May 2009. A total of 311 patients belonging to age group (20-80) years, presenting to the out-patient department with second to fourth degree utero-vaginal prolapse without any severe medical and surgical problems were included in this study. All the patients who had undergone vaginal hysterectomy during the study period and met the inclusion criteria were included in this study. The data collected was analyzed with standard statistical method (SPSS statistics 16.0).

Results: Total of 311 women were included in this study between the age group (20-80 years) with pelvic organ prolapse (second to fourth degree). All of them underwent vaginal hysterectomy. Among them 39 (12.5\%) had complications. The most common complication was secondary haemorrhage accounting for eleven $(28.2 \%)$ of all complications. Eight (20.5\%) patients had retention of urine, four (10.3\%) had headache, three $(7.7 \%)$ patients had primary haemorrhage, three $(7.7 \%)$ had pelvic cellulitis, three (7.7\%) had UTI, three (7.7\%) vault abscess, one (2.6\%) had bladder injury, one $(2.6 \%)$ had pelvic peritonitis, one $(2.6 \%)$ had vault prolapse. We had one death due to septicemia following seven days of post operation.

Conclusion: In our study, complication of vaginal hysterectomy was 39 (12.5\%) out of 311 patient. The most common complication being secondary haemorrhage 11 (28.2\%).

Key words: Pelvic organ prolapse, Reproductive age, Vaginal Hysterectomy.

\section{INTRODUCTION}

\begin{abstract}
A prolapse is downward displacement of one of the pelvic organs from its normal location. Traditionally, prolapse is referred to displacement of the bladder, the uterus or the rectum. These displacement have usually been graded on a scale of zero to three (or four); the grade increases with increasing severity of the prolapse, with zero referring to no prolapse and three (or four) referring to total prolapse ("procidentia"). All forms of female genital prolapse are described with reference to
\end{abstract}

Address for correspondence

Dr. Laxmi R.C.

Assistant Professor

Department of Obstetrics and Gynecology.

Patan Academy of health Sciences,

Lalitpur Nepal

E-mail: dr_lax50@hotmail.com the vagina'. These are often accompanied by urinary, bowel, sexual, or local symptoms. Although conservative treatment is enough for mild prolapse, the primary management of severe prolapse is surgical'.

The global prevalence of Pelvic Organ Prolapse (POP) is estimated to be $2-20 \%$ in women under age of 45 years. In Nepal, over $25 \%$ of women in rural areas are estimated to be suffering from pelvic organ prolapse (POP) ${ }^{2}$. Range of etiological factors includes congenital weakness of tissues, parity, aging and life-style, the most significant being advancing age and parity. The most commonly perceived causes of prolapse were lifting heavy loads, including the postpartum period ${ }^{2}$. Additional reason for increasing intra abdominal pressure were excessive workload, heavy sneezing during the postpartum period, chronic cough, pounding rice, defecating, 
climbing trees, heavy lifting during pregnancy and during menstruation ${ }^{2}$.

Vaginal hysterectomy is the removal of the uterus by the vaginal route. This method is safe with less complications in comparison to abdominal route ${ }^{3}$. Vaginal hysterectomy is the one of the most common surgical procedures, second to caesarean delivery ${ }^{4}$.

Advantages of vaginal hysterectomy are: it enables removal of a normal to slightly larger-than-normal uterus and small uterine fibroids when compared with abdominal hysterectomy, requires a shorter hospital stay, usually has a faster recovery than an abdominal hysterectomy, tends to cause less pain during recovery than after an abdominal surgery and does not leave scars on the abdomen 5 .

Vaginal hysterectomy is being carried out in different parts of Nepal with the financial support from international non-government organization ${ }^{6}$.

\section{METHODS}

A prospective observational study was carried out at Lord Buddha Educational Academy Nepalgunj Medical College (NGMC) Kohalpur Banke Nepal from November 2008 to May 2009. Ethical clearance was taken from the research committee, NGMC.

Among all the cases of vaginal hysterectomy during the study period, 311 (47.5\%) women met the inclusion criteria were included in this study. Ward Mayo's operation (vaginal hysterectomy, anterior colporrhaphy and posterior colpoperineorrhaphy) ${ }^{3}$ was performed.

Those patients who were not fit for anesthesia, other conditions like past history of myocardial infarction, valvular heart disease, stroke cases that were at operative risks, patient who denied to be included in the study, surgical correction other than vaginal hysterectomy whose women desirous of further children were excluded from the study.

Most of the patients were discharged on fourth post operative days without complaints and advised follow up if necessary. With complaints the patients were readmitted from the emergency and outpatient department and managed accordingly. Follow up was done on OPD basis at six weeks, three months and six months after surgery.

The data collected was analyzed with standard statistical method (SPSS statistics 16.0).

\section{RESULTS}

All the patients were housewives and all had home deliveries.

Total number of complications occurred in 39 (12.5\%) out of 311 patients.

Most of our patients belonged to para three to six, maximum parity was 15 and one $(0.3 \%)$ of our patient was nulliparous. Para five (18\%) and para three (16.1\%) followed by para six (14.1\%) and para four (13.5\%).

Ninety five patients $(30.5 \%)$ had history of prolonged labour, 48 (47.6\%) women had history of stress incontinence. 121 (39\%) women were smokers, Seven (2.2\%) were alcoholic, 24 (7.7\%) were both alcoholic and smoker, 151 (51.1\%) were nonsmoker and nonalcoholic. $16(5.1 \%)$ women had history of constipation. The mean duration of operation was 64.41 minute and mean number of days of hospital stay was nine days where maximum patient was discharged on fifth days.

Most common complication was secondary hemorrhage in $11(28.2 \%)$ patients, followed by retention of urine in eight (20.5\%) patients. Spinal headache was the third most common complication in four (10.3\%) patients.

Table 1: Distribution of the patients according to age group.

\begin{tabular}{|ccc|}
\hline Age group & Frequency (n) & Percentage (\%) \\
\hline Up to 30 & 28 & 9.0 \\
\hline $31-40$ & 68 & 21.9 \\
\hline $41-50$ & 96 & 30.9 \\
\hline $51-60$ & 94 & 30.2 \\
\hline $61-70$ & 24 & 7.7 \\
\hline$>70$ & 1 & 0.3 \\
\hline Total & $\mathbf{3 1 1}$ & $\mathbf{1 0 0}$ \\
\hline
\end{tabular}

Table 2: Duration of prolapse in years.

\begin{tabular}{|ccc|}
\hline $\begin{array}{c}\text { Duration of } \\
\text { prolapse (in years) }\end{array}$ & Frequency (n) & Percentage (\%) \\
\hline Up to 5 & 56 & 18.0 \\
\hline $6-10$ & 63 & 20.3 \\
\hline $11-15$ & 71 & 22.9 \\
\hline $16-20$ & 67 & 21.5 \\
\hline $21-25$ & 25 & 8.0 \\
\hline $26-30$ & 15 & 4.8 \\
\hline $31-35$ & 6 & 1.9 \\
\hline$>36$ & 8 & 2.6 \\
\hline Total & $\mathbf{3 1 1}$ & $\mathbf{1 0 0 . 0}$ \\
\hline
\end{tabular}


Other complications were pelvic cellulitis, primary hemorrhage, urinary tract infection and vault abscess in three $(7.7 \%)$ each. One $(2.6 \%)$ patient expired due to septicemia (Escherichia coli).

Maximum complications were managed conservatively (intravenous fluid and paracetamol for spinal headache, continuous bladder drainage for retention of urine) in $24(61.5 \%)$ patients and 15 (38.46\%) patients were managed surgically.

Table 3: Complication according to parity.

\begin{tabular}{|ccc|}
\hline Parity & Frequency(n) & Percentage(\%) \\
\hline 2 & 3 & 7.7 \\
3 & 9 & 23.1 \\
\hline 4 & 8 & 20.5 \\
\hline 5 & 4 & 10.3 \\
\hline 6 & 3 & 7.7 \\
\hline 7 & 3 & 7.7 \\
\hline 8 & 4 & 10.3 \\
\hline 9 & 2 & 5.1 \\
\hline 10 & 2 & 5.1 \\
\hline 11 & 1 & 2.6 \\
\hline Total & 39 & $\mathbf{1 0 0 . 0}$ \\
\hline
\end{tabular}

Table 4: Types of surgical management for haemoperitonium

\begin{tabular}{lcc}
\hline Type of surgery & No & \% \\
\hline Laparotomy & 9 & 20.5 \\
Pelvic drainage & 5 & 15.3 \\
Bladder repair & 1 & 2.6 \\
Total & $\mathbf{1 5}$ & $\mathbf{4 1 . 0}$ \\
\hline
\end{tabular}

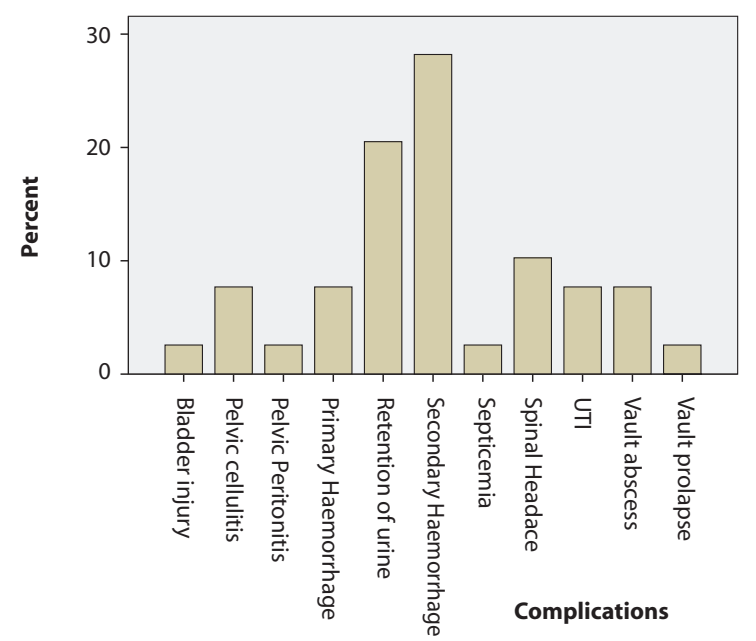

\section{DISCUSSION}

The incidence of uterine prolapse is found to be $26.85 \%$. Total number of women attended outpatient department was 5549 out of which 1490 women were diagnosed uterine prolapse. The rate of uterine prolapse as quoted by others; $25.1 \%$ (2000). Prevalence of utero vaginal prolapse is reported to be less common in Asian women $^{8}$. But, found to be high prevalence in Nepalese. (FHD, GTZ and UNFPA) in western Nepal and in 'Bhajang' $18 \%$, (Gurung G et $\mathrm{al}^{9}$.). which is more or less similar to this study. Incidence in other countries: $17 \%$ in Australia and US, 8.5\% in France which is less than this study but $27 \%$ in Istanbul ${ }^{13,14}$ which is consistent with this study. According to Pradhanang $\mathrm{V}$ et $\mathrm{al}^{10}$ incidence of POP in Nepal is $11.1 \%$ which is much lower than this study.

In this study, maximum number of cases was in the age group of 41 to 50 years (30.87\%). Global prevalence of uterine prolapse is quoted as (2-20\%) even under the age of 25. In a study in western Nepal majority of women who underwent hysterectomy belonged to age group of 30-50 years according to Renjhan $\mathrm{P}$ et $\mathrm{al}^{11}$, which is consistent with this study. The maximum (30.87\%) cases are in the age group of 41-50 years. This age group of 41-50 years was also more common for POP in western Nepal (Pradhanag V et al) ${ }^{10}$.

Maximum number of patients in this series were belonged to para five. Hence, we can assume that multiparity is related to the increasing incidence of POP.

Seventy one cases (22.8\%) in this study group had prolapse of 11-15 years duration followed by 67 (21.5\%) from 16-20 years duration. In this series, years of suffering were more as compared to Gurung $\mathrm{G}$ et $\mathrm{al}^{9}$. In their study they continue suffering to many years up to 10 years or more in $(73.9 \%)$ of prolapse, one in every third women (30.4\%) noted prolapse after the first child birth. In present study, duration of labour (from the patient's history) was 12-24 hours in 95 cases (30.5\%), undue stretching of pelvic supports or inherent weakness might be responsible for POP.

In the present study, 16 (5.1\%) women had history of constipation, 121 (39\%) were smokers, 7 (2.2\%) alcoholic, 24 (7.7\%) were both alcoholic and smoker, 151 (51.1\%) were non smoker and non alcoholic. The habit of smoking and alcohol may be due to social conditions; the cold climate and habitat (high altitude) which may have resulted in chronic disease or cough activating factors for causation of prolapse and postoperative complications.

Figure 1: Types of complications 
In this study, 148 (47.6\%) women had stress incontinence. It is concluded that half of the cases of POP will have stress incontinence which is a psycho-social distress especially in female patients in our society.

Postoperative complications rate in this series was $12.5 \%$ where as $8.6 \%$ was found by Pradhanang $V$ et al ${ }^{10}$. Dissimilarity is possibly due to different socio-economic and nutritional status.

In this study, secondary hemorrhage in 11 (28.2\%) was most common complication but Shah $\mathrm{CM}^{12}$. found significant rise in temperature (31\%) whereas hemorrhage to compare with this study was $20 \%$, which is less $(8 \%)$ than this study. Pradhanag $V$ et $\mathrm{al}^{10}$. found spinal headache was common $(4.8 \%)$ complication followed by retention of urine (1.4\%), secondary haemorrhage $(0.3 \%)$, pelvic abscess $(0.6 \%)$, haemoperitonium (0.3\%). Saha R. et al ${ }^{4}$. found secondary hemorrhage in $6 \%$ of cases.

\section{REFERENCES}

1. Menefee SA, Wall LL. Incontenence, prolapse and disorders of the pelvic floor. In: Berek JS, Rinehrt RD, editors. Novak's Gynecology, $13^{\text {th }}$ Edition. Philadelphia: Lippincott Williams and Wilkins; 2002.p.686.

2. Listening to 30 "felt needs": investigating genital prolapse in western Nepal. (Issues in Current Service Delivery). Goliath business news: reproductive health matters. 2004;p.1-10.

3. Dawn CS. Retrovertion of uterus, hypertrophy and elongation of cervix, genital prolapse. Textbook of gynecology, contraception and demography. $14^{\text {th }}$ edition. Kolkata: Dawn books; 2003.p.120-5.

4. Saha R, Sharma M, Padhye S, Karki U, Pandey S, Thapa J. Hysterectomy: an analysis of perioperative an postoperative complication. Kathmandu university medical journal. 2003;1(2):124-7.

5. Duniz M. Complications, morbidity and mortality of vaginal hysterectomy In: Sheth S, John S, editors. Vaginal hysterectomy. London: Gopsons Papers; 2002.p.341-51.

6. Shah CM. Vaginal hysterectomy: indications and complications. Canadian .Family Physician.1970 May; $72-4$
In present series, one postoperative death occurred due to septic shock following haemoperitonium. The presence of low grade fever did not appear to alter the postoperative course.

In this study, postoperative UTI was found in $7.7 \%$ of the cases. Postoperative UTI was very common in the study of Maudesley RF et al ${ }^{12}$. they reported postoperative UTI in $48 \%$ of cases. In another study, Shah $\mathrm{CM}^{6}$ reported postoperative UTI in $18 \%$ of the patients which was also common and higher than present study.

In this study different other complications which were observed are retention of urine (5\%), spinal headache (10.3\%), vault abscess $(7.7 \%)$, pelvic peritonitis $(7.7 \%)$, pelvic cellulitis $(7.7 \%)$, which were more as compared to Pradhanag $\mathrm{V}$ et $\mathrm{al}^{10}$. and other workers.

\section{CONCLUSION}

In our study the most common complication is secondary haemorrhage 11 (28.2\%).

7. Howkins and Bourne. Genital prolapse. In: Padubidri VG, Daftary SN, editors. Shaw's textbook of gynecology. $13^{\text {th }}$ edition. New Delhi: Elsevier. 2004.p.320-2.

8. Nicholas DH, Randal CL. Vaginal surgery, Baltimore: Williams and Wilkins; 1989.p.313-27.

9. Gurung G, Rana A, Amatya A, Keshang DB, Joshi AB, Sayami J. Pelvic organ prolapse in rural Nepalese women of reproductive age groups: what makes it common. N J Obstet. Gynaecol. 2007;2(2):35-41.

10. Pradhanang V, Tuladhar H, Maskey S, Dali SM, Pradhan P. Review of hysterectomies at NMCTH: a retrospective study. Journal of Nepal health research council. 2005;3(1):34-8.

11. Renjhan $P$, Behura $S$, Acharya $S$. Trends in hysterectomy for benign causes: A retrospective study at Kohalpur teaching hospital. Journal of Nepal medical association. 2003;42:156-9

12. Maudesly RF, Robertson EM.Common complications of hysterectomy. Canad. Med. Ass. J 1965;92:908-11.

13. Hendrix SL, Clark A, Nygaard I. Pelvic organ prolapse in the women's health initiative: gravity and gravidity. Am J Obstet Gynecol. 2002;186(6):1160-6.

14. Bulut A, Filippi V, Marshall T. Contraceptive choice and reproductive morbidity in Istanbul. Studies in family Planning. 1997;28(1):35-43. 